\title{
Looking back, moving forward: Reducing HIV-related stigma, Horizons studies 2000 to 2007
}

\author{
Julie Pulerwitz \\ Population Council \\ Annie P. Michaelis \\ Ellen Weiss \\ Population Council \\ Lisanne Brown \\ Vaishali Sharma Mahendra
}

Follow this and additional works at: https://knowledgecommons.popcouncil.org/departments_sbsr-hiv

Part of the Demography, Population, and Ecology Commons, Family, Life Course, and Society

Commons, International Public Health Commons, and the Medicine and Health Commons

How does access to this work benefit you? Let us know!

\section{Recommended Citation}

Pulerwitz, Julie, Annie P. Michaelis, Ellen Weiss, Lisanne Brown, and Vaishali Sharma Mahendra. 2010. "Looking back, moving forward: Reducing HIV-related stigma, Horizons studies 2000 to 2007," Horizons Synthesis Background Papers. Washington, DC: Population Council. Version of record: https://doi.org/ $10.1177 / 003335491012500218$ 


\section{LOOKING BACK, MOVING FORWARD}

\section{Reducing HIV-Related Stigma}

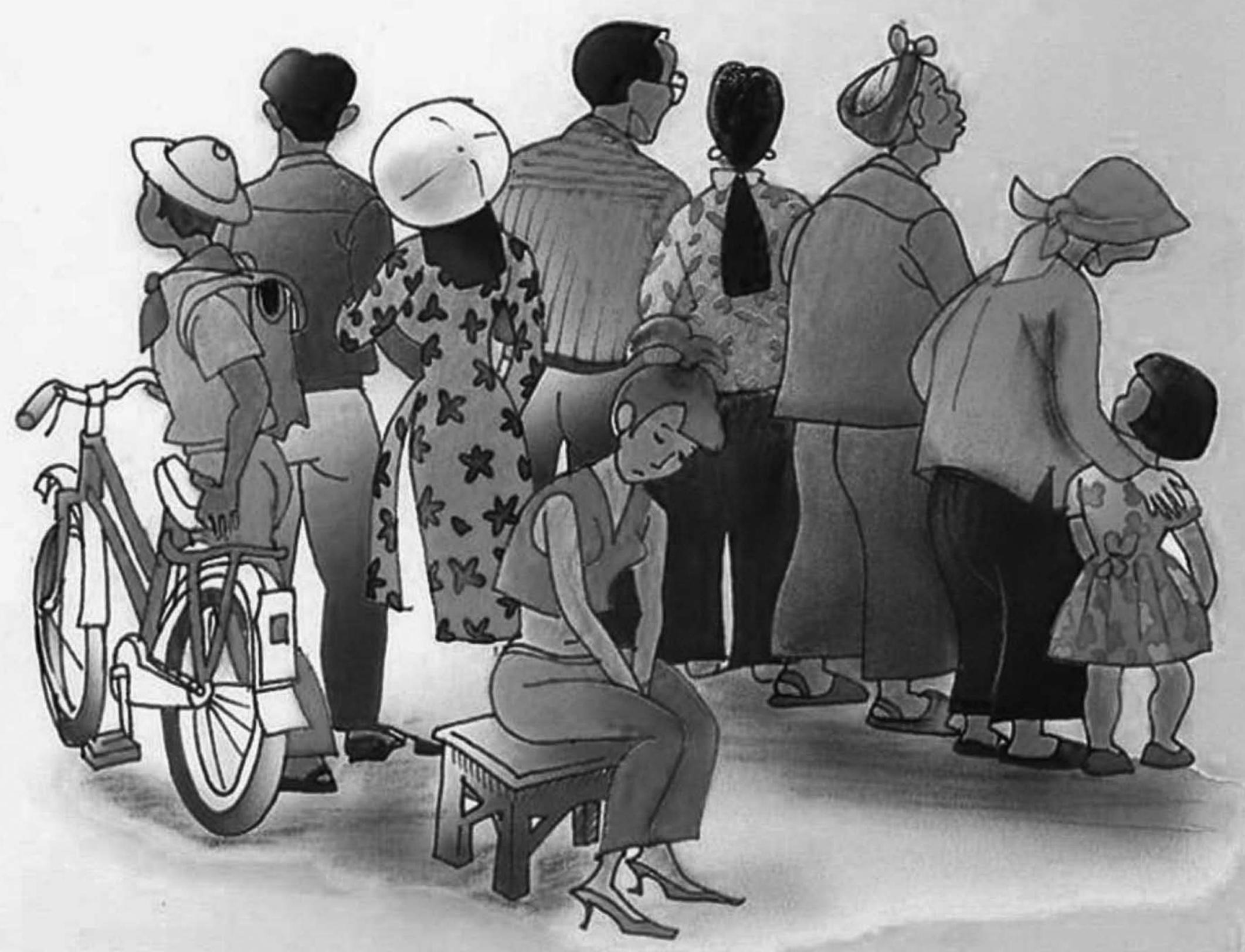

HORIZONs StUdiEs 2000 TO 2007 


\section{Hgrizons}

In 1997, the Population Council initiated the Horizons Program—a decade-long USAID-funded collaboration with the International Center for Research on Women, the International HIV/AIDS Alliance, PATH, Tulane University, Family Health International, and Johns Hopkins University-designing, implementing, evaluating, and expanding innovative strategies for HIV prevention and care.

Horizons developed and tested ways to optimize HIV prevention, care, and treatment programs; worked to reduce stigma and improve gender-biased behaviors; and greatly expanded knowledge about the best ways to support, protect, and treat children affected by HIV and AIDS. In all its projects, Horizons strengthened the capacity of local institutions by providing support and training to colleagues.

This series of synthesis papers presents lessons learned and best practices on six key topics that Horizons investigated: HIV-related stigma, access to antiretroviral therapy, men who have sex with men, orphans and vulnerable children, HIV and gender, and prevention of mother-to-child transmission of HIV. 


\section{Reducing HIV-related Stigma}

Addressing stigma about HIV and AIDS at the individual, institutional, and governmental levels was a priority throughout the Horizons Program. We documented that stigma can take many forms, from abuse of people with HIV to denial of services. Many people and institutions are unaware that they harbor stigmatizing beliefs or that their actions promote these beliefs. Over the years, Horizons' operations research showed that it is possible to measure stigma and to develop effective strategies to reduce it. Successful strategies include: using education to correct misconceptions about the transmission of HIV, involving people living with HIV in the program to give AIDS a human face, and engaging the community in the care and support of people living with HIV.

\section{Introduction}

Early in the HIV epidemic's history, the late Jonathan Mann, former head of WHO's Global Program on AIDS, identified stigma as the "third epidemic," following the accelerating spread of HIV infection and the visible rise in AIDS cases. He recognized that stigma, discrimination, blame, and denial are potentially the most difficult aspects of HIV and AIDS to address. Yet tackling these challenges is key to preventing HIV transmission and alleviating the effects of the disease on individuals, families, and communities [1].

When the Horizons Program began in 1997, stigma's insidious role in the spread of HIV was widely recognized, and a few programs attempted to address its impact. Yet despite this increased awareness, there was limited understanding of the underlying drivers of stigma. There were few tools to reliably and effectively measure stigma and discrimination. And there was a dearth of information about which types of intervention strategies most successfully reduce stigma in different settings.

In response, Horizons developed and implemented a wide range of activities in collaboration with numerous local and international partners in Africa, Asia, and Latin America. This paper summarizes the key contributions of the Horizons stigma portfolio. The program of research described the drivers of stigma, identified effective interventions and approaches for reducing stigma in different settings, and improved methods for measuring stigma. 


\section{Taking Stock of Current Knowledge}

Horizons initially carried out three key activities to take stock of what was known about HIV-related stigma and ways to reduce it. In 1999, Horizons co-hosted a technical workshop with San Francisco State University that brought together experts on stigma and HIV. The program then published a literature review of stigma intervention strategies [2]. Next, researchers from Horizons examined existing conceptual frameworks on stigma and discrimination. Finally, we built upon these frameworks to develop new approaches for intervening and reducing stigma in various contexts [3].

Findings from these activities showed:

- Stigma occurs at many levels, including the interpersonal, institutional (e.g., health facilities, schools, workplaces), community, and legislative levels.

- Manifestations of stigma take many forms, including isolation, ridicule, physical and verbal abuse, and denial of services and employment.

- Experiences of stigma can differ by sex, reflecting broader gender inequalities. For example, women may be more likely to be blamed for bringing HIV into the household then men.

- HIV-related stigma is tied to and reinforces existing stigmas against marginalized groups (e.g., men who have sex with men, sex workers, injection drug users)—often called "compounded" stigma.

- Common stigma reduction interventions have focused mainly on creating changes in individual knowledge, attitudes, and behaviors rather than broader social and environmental change.
- There have been very few rigorous evaluations of programs to reduce stigma in the developing world.

What Horizons learned about stigma early on-that it's a deeply rooted social process with different manifestations at various levels of society-had important implications for the development of our global operations research agenda.

\section{Developing and Improving Research Measures}

Horizons actively collaborated with other members of the USAID-convened Stigma and Discrimination Indicator Working Group to develop quantitative measures of stigma and address gaps in measurement. These were field tested in Tanzania [4] and retested in a Horizons intervention study, also in Tanzania [5].

Horizons and partners incorporated these measures and instruments into many of the studies described throughout this paper, which took place in different settings (e.g., hospitals in India and Vietnam; communities in Nicaragua and Tanzania). Horizons also collaborated with the World Health Organization to develop a generic survey tool designed to measure stigma and discrimination across multiple settings [6].

\section{Measuring the various facets of stigma}

Measuring multiple dimensions or "domains" of stigma and discrimination is critical to accurately capturing existing stigma as well as changes due to an intervention. As part of Horizons' ongoing collaboration with partners (including, USAID, International Center for Research on Women, and others), four key dimensions of stigma have been articulated and tested: 
- Inappropriate fear of contagion: Measures focus on attitudes that reflect fear of contagion and HIV transmission from casual contact with people living with HIV.

- Negative judgments about people living with HIV: Measures focus on attitudes that reflect blame, shame, and casting moral judgments on HIVinfected people.

- Enacted stigma or discrimination: Measures encompass both interpersonal forms of discrimination (e.g., being isolated or teased) and institutional forms of discrimination (e.g., being fired from work or denied health care because of HIV).

- Compounded stigma: Measures focus on perceptions of the association between HIV and certain (usually marginalized) groups, such as sex workers.

Horizons researchers focused on developing clear and precise survey items that can be used in diverse settings, and which measure each of these multiple dimensions of stigma and discrimination (Table 1). Earlier instruments were limited by a focus on fear-of-contagion items, to the exclusion of measures of the social dimensions of stigma (that is, negative or valueladen judgments about people with HIV). Demonstrating that all dimensions of stigma are relevant has had important implications for developing appropriate intervention strategies. In India, the researchers developed and tested an index to measure the various dimensions of stigma in health care settings, including attitudes about personal contact with HIV-positive people, blaming and judgmental attitudes, and support for discriminatory hospital practices. Baseline findings using the index helped inform the intervention, and comparisons with endof-study findings provided evidence that stigma had been reduced in the hospital setting $[7,8]$.

The following section highlights findings from Horizons intervention studies (see Appendix for a complete list), which tested a range of innovative stigma-reduction strategies implemented at the institutional and community levels to achieve individual and social change.

\section{Stigma-reduction Strategies}

\section{Helping institutions recognize stigma}

Horizons and partners recognized from the outset that to improve the environment for people with HIV in health care settings, it was important for management and health providers to acknowledge that stigma exists in their facilities. They found that a participatory approach helped build staff and management support for stigma-reduction activities. This approach included sharing information about the levels and types of stigma among employees in their institutions.

In a study conducted in three public and private hospitals in New Delhi, India, hospital 
managers were initially unwilling to believe that stigma and discrimination existed in their hospitals. Baseline data from interviews with health workers and HIV-positive patients, as well as a survey of nearly 900 workers, suggested otherwise. After the research team shared key findings, the hospital managers and staff developed action plans to address hospital workers' misconceptions about HIV transmission, as well as their judgmental attitudes and differential practices toward HIV-positive individuals. These action plans involved dealing with limited supplies for practicing universal precautions, educating providers about HIV transmission and sensitizing them to the needs of people living with HIV, and increasing management support.

To help develop the action plans and set institutional goals, the project team created a checklist allowing hospital managers to examine how well their facility provides a safe working environment for staff and a welcoming environment for HIV-positive patients. During the evaluation of the intervention, the hospital managers reported that the availability of data on stigma and discrimination and the use of the checklist showed staff members how HIV-positive patients were treated differently in their hospitals, and helped catalyze reform [7].

Similarly, Horizons staff shared baseline findings on stigma and discrimination with hospital management at a facility in Vietnam. These professionals then became enthusiastic participants in subsequent intervention activities to improve care for people with HIV and safeguard the health of hospital workers [9]. This approach of proceeding gradually and involving staff in a non-confrontational manner, which Horizons proposed and evaluated, resulted in hospital managers welcoming the opportunity to make needed changes in policies and practices.

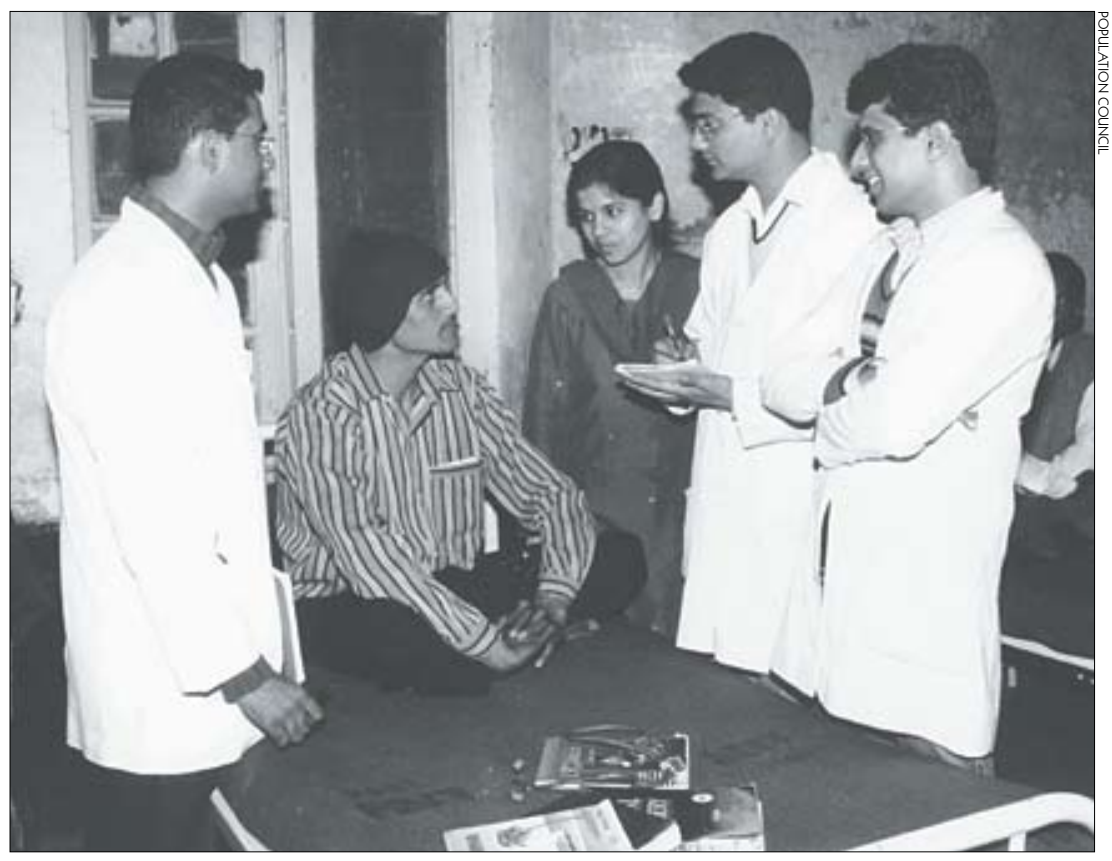

Horizons research in India demonstrated the need for a participatory approach to address stigma and discrimination in the hospital setting.

\section{Addressing HIV-related stigma in hospitals}

The hospital-based intervention study in India focused on helping facilities establish an environment that provided timely, appropriate, and humane care for people with HIV. This required developing tailored interventions to protect the interests and well-being of both patients and hospital staff. To catalyze social and environmental changes, the project team engaged hospital managers in a participatory process for developing stigma-reduction action plans. These action plans included establishing an HIV and AIDS care and management policy, enlisting people living with HIV to train health care workers and make them aware of the needs of HIV-positive people, strengthening HIV counseling and bringing it into the mainstream of care, and developing and disseminating information on infection control procedures and the availability of post-exposure prophylaxis to staff.

After the intervention, health care workers' attitudes toward people with HIV and the 
quality of care offered to them improved. For example, the proportion of health care workers who, based on their scores on a stigma index, were categorized as having the least stigmatizing attitudes doubled (12 percent vs. 27 percent) (Figure 1), and the proportion of respondents with the most stigmatizing attitudes declined considerably (24 percent vs. 7 percent).

Counseling and testing practices and protection of patient confidentiality also improved, as did understanding and use of universal precautions with all patients [7].

In Vietnam, Horizons and partners built on the results of the India study by conducting intervention research in four hospitals, involving nearly 800 hospital workers. Activities included training for all levels of hospital staff (for example, nurses, janitors, and others) on HIV

\section{"If HIV-infected patients are at stage one their stuff is sterilized... if they are at stage two and we are aware of their infection through HIV tests, their stuff is incin- erated.... It is both the hos- pital regulation and what we think should be done."}

- Orderly from Vietnam hospital and universal precautions, bringing in people living with HIV to speak about their experiences as part of staff training workshops, involving staff members in the development of hospital policies, and making key upgrades in the structural environment (for example, improving the availability of hand-washing facilities and providing sturdy containers to dispose of needles and syringes). Two hospitals received these activities alone, while the other two received the same package of activities plus a half-day workshop focused on the causes and manifestations of social stigma. The workshop was co-facilitated by people living with HIV.

Following the intervention, hospital practices improved. There were significant declines in the labeling of patients' files and beds with their HIV status. The overuse of barrier protections (e.g., using gloves during casual contact with HIV-positive patients) was reduced. And, there was better hospital-wide implementation of universal precautions.

Health workers in all four participating hospitals significantly improved their mean scores on both fear-based and socially based stigma indices $(\mathrm{p}<$ 0.05). While both interventions successfully reduced stigma, results from hospitals with the extra half-day staff workshop on social stigma showed significantly more impact. For example, workers in these hospitals were 4.7 times less likely to report marking the files of HIV-positive patients ( $\mathrm{p}$ $<0.001$ ) and 2.3 times less likely to report placing signs on beds indicating HIV status ( $\mathrm{p}<0.001)$, compared to workers at the other two hospitals [9]. 


\section{Providing non-stigmatized health services}

In Brazil, formative research showed that truck drivers, a population often at increased risk of HIV infection, were wary of HIV services because of the stigma attached to accessing the services [10, 11]. In response, Horizons and partners tested a model combining HIVrelated services with general health services and targeted them to truckers. A health unit was established inside a border customs station in southern Brazil that provided a variety of services. These included voluntary counseling and testing for HIV and other sexually transmitted infections (STIs), identification and treatment of STIs based on characteristic signs and symptoms (syndromic management), and dissemination of information on HIV and STIs. These services were incorporated into a comprehensive package that also included basic health services not related to sexual health (such as blood pressure monitoring and glucose testing).

This holistic strategy was well received by truckers. An added benefit was that many truckers seeking non-HIV related services ended up participating in HIV/STI educational discussions. For example, when health educators began group discussions or activities, a number of the drivers seeking only blood pressure and glucose measures stayed to listen and learn about HIV and AIDS (Box 1).
At baseline, less than half of the respondents had ever had an HIV test. By follow-up, the number of truckers who had ever had an HIV test increased by 49 percent in the intervention site, but only by 15 percent in the comparison site $(\mathrm{p}<0.01)$. The majority of participants reported that they found the services useful and non-stigmatizing [10].

Men who have sex with men are another highly stigmatized population that faces barriers to HIV services because of stigma. In Senegal, Horizons and partners found that the stigma and discrimination suffered by many men who have sex with men leads them to conceal sexual behaviors from health care providers. This makes it difficult for these men to receive appropriate STI services [12]. The project team worked to create and train a network of health providers sensitized to the special needs of men who have sex with men. These providers were able to provide confidential, nonjudgmental medical and psychosocial care. Qualitative findings at the end of the intervention showed that men appreciated the availability of STI services, which they found to be of high quality and non-stigmatizing. According to a 23-yearold informant, "They are doing a wonderful job because they are available when we need them, and they are not judgmental" [13].

\section{Box 1 Truckers' perception of the intervention: Non-stigmatizing, accessible, and useful}

They teach you that AIDS can be transmitted, that it is dangerous, that it can kill you, but also that there are ways of treating it. The education is really very good.

FGD, Paraguayan user

I went there three times to take the blood pressure exam, apart from the main (VCT) exam that I did the first time I was invited. After that, from time to time I go back there to get condoms...

FGD, Brazilian user

This service was the best thing in this region. Now, you have a problem and you have all you want here, not needing to go to other places - and you use the time when you are waiting for your cargo authorization papers. 


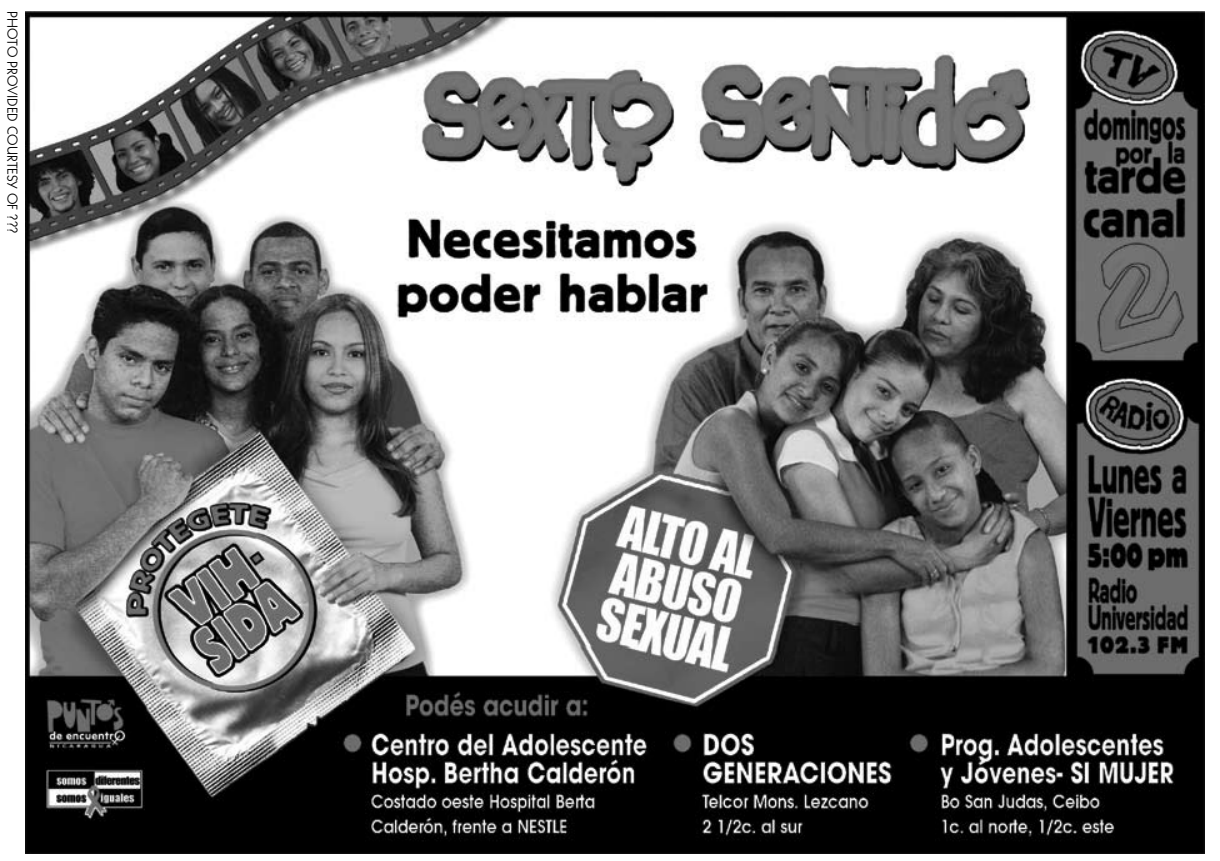

Horizons helped evaluate a communications-for-social-change strategy in Nicaragua that included a national television soap opera series called Sexto Sentido that addressed issues of stigma, gender inequality, and violence. attitudes than individuals with less exposure. After controlling for sociodemographic variables, the high-exposure group demonstrated a 20 percent greater reduction in stigmatizing attitudes $(\mathrm{p}<0.001)$ compared to the lower exposure group.

Qualitative data suggest that the soap opera reduced stigmatizing attitudes by helping viewers relate to affected individuals as human beings who have rights and need compassion and support. The study also found that some aspects of stigma and discrimination are easier to change than others. For example, it was more difficult to change the perception that men who have sex with men and sex workers are vectors of HIV, even though other stigmatizing attitudes were significantly reduced among those exposed to the intervention. These results demonstrate the complexity of stigma as an intervention outcome and that one intervention strategy may not address all aspects of stigma and discrimination [14]. sought to empower young men and women to improve prevention of HIV infection through critical discussion of social and cultural issues (for example, stigma, gender inequality, and violence). To address these issues in an accessible and entertaining way, the project team created: 1) a national television soap opera series called Sexto Sentido (Sixth Sense), 2) a youth-directed radio show, and 3) various community-based activities (for example, training youth leaders, networking with other NGOs to reinforce intervention messages, and creating advocacy networks) [14].

A representative cohort intervention study of more than 3,000 young people from three large cities over two years, found that individuals most exposed to the intervention were significantly less likely to hold stigmatizing

\begin{abstract}
A Horizons intervention study in Senegal found that the media contribute to the stigmatization of men who have sex with men by communicating negative and sensational stories about them. As part of intervention activities, the project team held a workshop for media representatives in Dakar that included the participation of men who have sex with men, whose lives are often punctuated by stigma, discrimination, and violence. This workshop helped journalists better understand the hidden realities of the men's lives and brought a human face to the issues. Over the next 18 months, the project team reviewed local newspapers and found that no offensive or stigmatizing articles had been written about men who have sex with men [13].
\end{abstract}




\section{Empowering people living with HIV by involving them in providing HIV services}

Horizons has found that efforts to involve people with HIV in providing HIV services and in sensitizing other service providers about the realities of their lives empowers HIVpositive individuals, improves service delivery, and contributes to stigma reduction among health workers and community members. Studies in Burkina Faso, Ecuador, India, and Zambia revealed that when programs provide adequate support and training to HIV-positive team members, involvement in NGO activities can reduce their isolation, enhance their selfesteem, and improve community perceptions about their productivity. Further, involvement of people living with HIV can improve care and support services by making them more relevant and personalized. As one HIV-positive peer counselor in India remarked, service recipients derive hope from seeing other HIVpositive individuals actively involved in delivering NGO services [15].

The hospital-based stigma reduction programs in Vietnam and India are other examples of successful collaborations with people living with HIV. In these interventions, health care workers heard—often for the first time-from HIV-positive trainers about living with HIV and began to relate to them as people, not just as patients $[7,9]$.

\section{Engaging the community}

Horizons and partners have developed and tested different stigma reduction strategies in the community. A Horizons study found that young members of Zambian groups known as "Anti-AIDS Clubs" can be trained to provide care and support to people with HIV and to help foster their acceptance within families and communities. The study examined young people in 30 anti-AIDS clubs who received training to become adjunct caregivers to families in their communities. They helped with

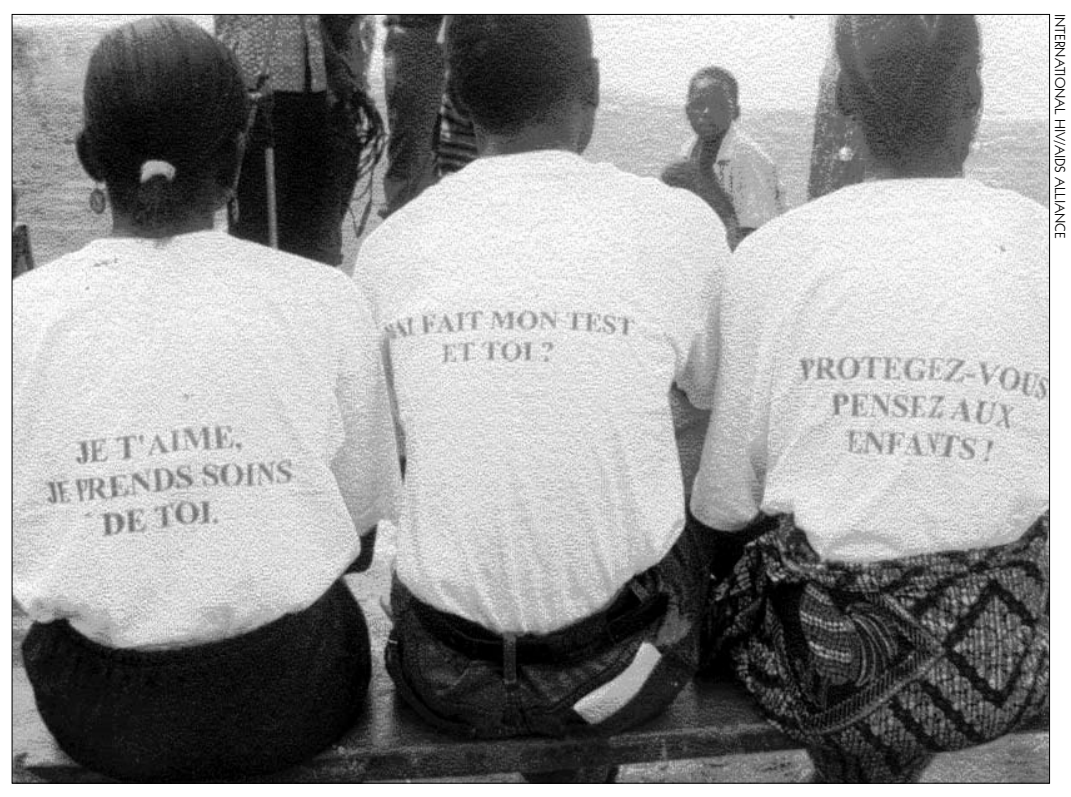

Members of RVS+ in Burkina Faso wear prevention messages during and HIV/AIDS awareness-raising campaign. From left to right: "I love you - I protect you," "I've been tested; have you?" and "Protect yourself_- think of the children."

domestic chores, bathed HIV-infected patients and dressed their wounds, and provided information, support, and referrals to family members. The study found that as a result of observing the activities of the young caregivers and interacting with them, family members got more involved in their relative's care. After learning about the program and witnessing the work of the young caregivers, community members began to see that they too could visit people with HIV. According to a client of the program, "Our community is beginning to accept people with AIDS since youth caregivers started visiting; they are not as fearful as before" [16].

Horizons and partners have also conducted quantitative evaluations of community-based stigma reduction interventions based on the framework in Figure 3. In Tanzania, a community-based organization trained their staff and volunteers, people living with HIV, and community leaders to recognize stigma, integrate stigma-reduction into their routine work, and carry out community sensitization and mobilization activities. Findings from community sur- 
veys and the qualitative methods showed that recognition of HIV-related stigma (for example, what it is, how it manifests) significantly increased over a two-year period. This is a key first step in the process of stigma reduction. At the end of the project, there were statistically significant decreases in stigmatizing attitudes associated with shame and blame among those exposed and not exposed to the intervention activities. However, findings showed that the intervention did not reduce stigma community wide. One explanation is that the intervention did not train enough people to saturate the study communities adequately enough to trig- ger population-wide reductions in stigma. On the other hand, the researchers found that the stigma reduction training had a profound effect on those trained, particularly the community leaders, leading to visible changes in their own behavior and leadership. A promising avenue for future efforts is equipping greater numbers of such opinion leaders with the skills and support necessary to reach more people [5].

A study by Horizons and partners in Rwanda found that households without an adult caregiver are often stigmatized by the community, resulting in high levels of social exclusion and

\section{Figure 3 Intervention framework for community-based stigma reduction to increase service utilization}

Wider social context: social, gender, and sexual norms; individual characteristics (e.g., sex, education, socioeconomic status)

Increase
$\begin{gathered}\text { recognition } \\ \text { of stigma }\end{gathered}$
Decrease
fear of
transmission
through
reduction
intervention
$\begin{gathered}\text { casual contact } \\ \text { Decrease } \\ \text { attitudes, } \\ \text { values, and } \\ \text { beliefs leading } \\ \text { to shame and } \\ \text { blame }\end{gathered}$

INCREASE

in outcomes

Prevention

(VCT)

Care

Treatment

(ART)

Disclosure

TRAJECTORY FOR CHANGE 
maltreatment. The project team developed and evaluated a volunteer adult mentorship program for youth-headed households to improve the psychosocial outcomes of its members. Analysis of pre- and post-intervention survey data collected from more than 1,300 young heads of household who did and did not participate in the adult mentorship program revealed significant improvements among participants [17].

Using a six-item scale that explored perceptions of isolation and stigma from the community, the researchers found that over the course of the two-year study, participants reported lower levels

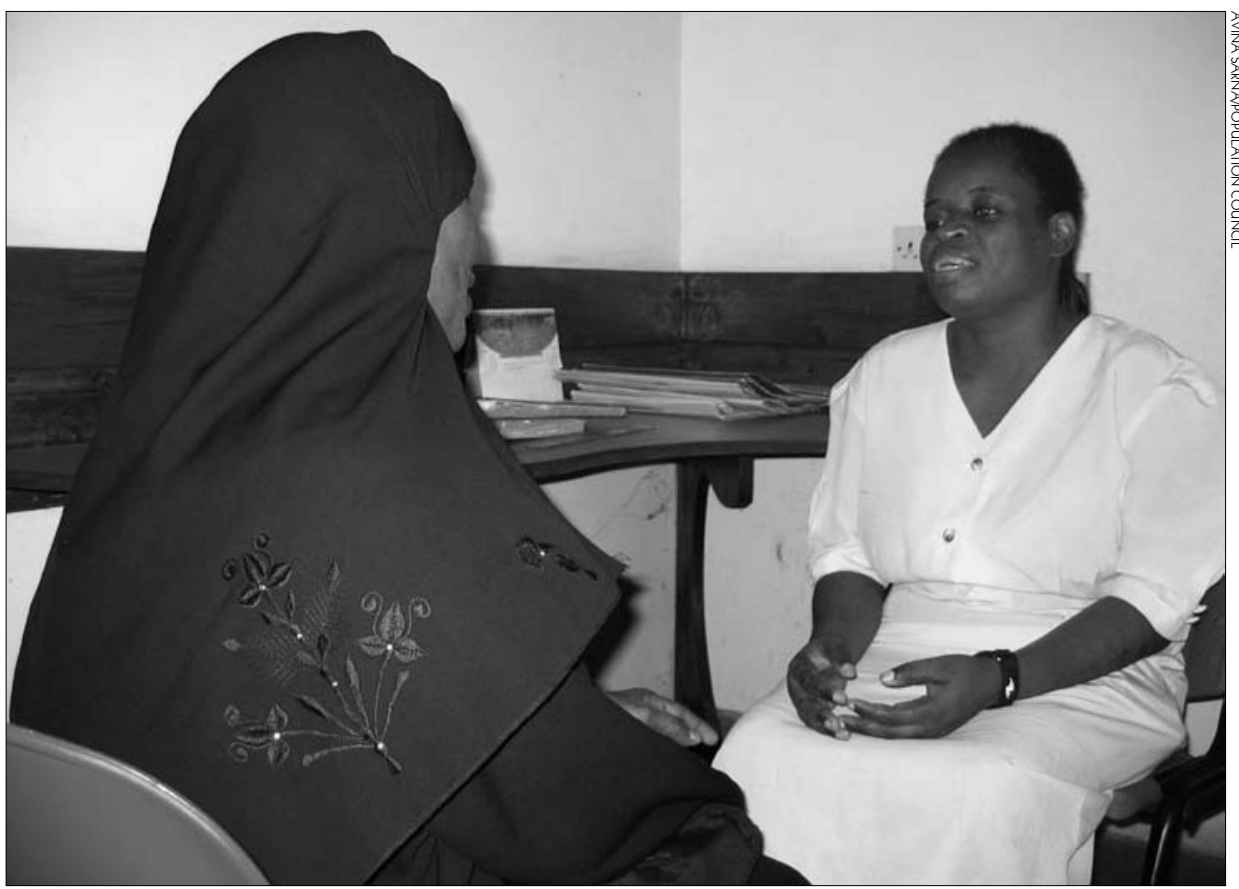

Patients on ART and receiving adherence counseling in Mombasa reported declines in internal stigma after 12 months on treatment in a Horizons study in Kenya. of marginalization at follow-up compared to baseline, while there was no change among the comparison group. After controlling for background variables, an intervention effect was still evident. The researchers also found positive changes when examining the impact of the program on experiences of maltreatment, including sexual abuse, exploitation, and theft [17].

\section{Impact of Expanded Antiretroviral Therapy}

Horizons studies also support the idea that increased accessibility and uptake of antiretroviral therapy has had a positive impact on stigmatizing attitudes and behaviors of community members and on internalized stigma (self-stigma or negative beliefs about themselves) among people living with HIV. In Zambia, in-depth interviews with people on antiretroviral

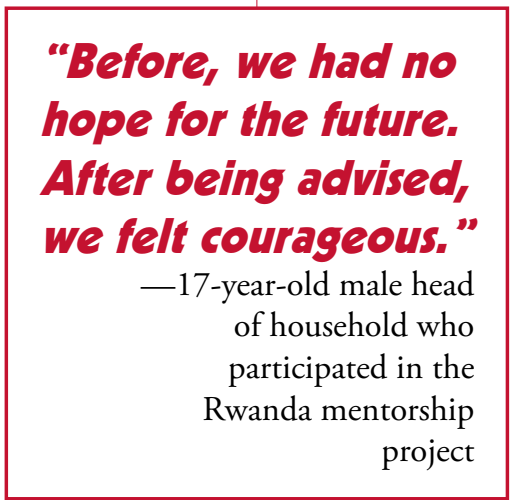

therapy (ART) in Lusaka and Ndola revealed a common perception that levels of stigma had dropped within the family and community, among health care workers, and in the workplace. All respondents credited the increased availability of ART with reductions in stigma, and increased awareness that becoming infected can happen to anyone, and that almost everyone is somehow affected [18].

These qualitative data support findings from a community survey which showed that levels of stigmatizing attitudes decreased in sites where there was either clinic-based or clinic- and community-based education about HIV and ART, as well as access to free treatment. Preand post-survey data among people on ART in one city showed significant reductions in internalized and experienced stigma, which was measured using a 24-item scale adapted from the HIV stigma scale [19]. But it is important to 
point out that there was no change in stigma levels in the second city over time and that, despite statistically significant reductions in community-level stigma across the study sites, suggesting that levels are still high enough to be of concern.

Findings from a Horizons study in Mombasa, Kenya, also found significant reductions in internalized stigma among a cohort of people taking ART and receiving adherence counseling. The research team measured internalized stigma with a 16-item scale, also adapted from the HIV stigma scale [19]. Nearly three-quarters of respondents reported moderate to high levels of internalized stigma at baseline, declining to 56 percent $(\mathrm{p}=0.001)$ after 12 months on treatment. The study also found that participants had disclosed their HIV status to a significantly greater number of family members after 12 months on treatment, from a median of two family members to a median of three at follow-up ( $<<0.001)$. However, there was no change in disclosure rates in the community or at the workplace. Interestingly, the Kenya study found that women had significantly higher levels of internalized stigma before initiating ART, but that this difference disappeared after a year on treatment [20]. A similar pattern was observed in the Zambia study among crosssectional samples of men and women who had just begun ART and among those interviewed two years later [18].

\section{Moving Forward}

The Horizons portfolio has made substantial contributions to understanding HIV-related stigma and discrimination and ways to reduce it. Specifically, Horizons and partners have articulated frameworks that guide how to address stigma and helped build a consensus around an approach to measuring stigma. We have shown that researchers can design intervention activities to address particular drivers of stigma. And we have confirmed that these interventions can reduce stigma among health workers and among family and community members, thereby contributing to improved quality of life for people living with HIV. The studies point to the positive role community organizations and the media can play in helping to empower HIV-infected individuals and changing community perceptions about them.

Horizons research also highlights the likely contribution of increased access to ART in reducing stigma among people living with HIV (internalized stigma) and in the general community.

However, given the magnitude of the problem, efforts to reduce stigma and measure the effects of interventions on stigma levels need to become a higher priority among program managers, policymakers, and donors. The conceptual frameworks and measures developed under Horizons need to be more widely used in the field. As the UNAIDS 2008 Report on the Global AIDS Epidemic states, "Horizons' part-
A woman living with HIV shares her experiences with hospital workers in Vietnam, as part of a Horizons intervention study adapted from an earlier study conducted in India. 
ners developed stable measures of stigmatizing attitudes (recognition, fear, and "blame and shame" components), events (isolation, verbal stigma, loss of identity and status, and loss of access to resources), and tools for measuring improvements in the environment that can be adapted and applied worldwide."

While the current focus on rapid treatment expansion is encouraging and will undoubtedly result in decreasing stigma, it is important not to neglect the types of community-based, media-focused, and institutional-level interventions in the Horizons portfolio that have demonstrated positive changes.

In addition to expanding proven intervention strategies, the field needs more operations research to refine approaches and fill knowledge gaps. In particular, more research is needed to understand the influence of interventions from the perspective of people living with HIV, particularly in health care settings. We also need to investigate whether there are any differential impacts by gender, age, and other factors. Such information is critical for assessing whether stigma reduction interventions have had a lasting impact on those most affected. Stigma reduction interventions with such marginalized and vulnerable populations as men who have sex with men, sex workers, and injecting drug users need to be further developed and evaluated. Also, efforts to better understand and address gender differences in internalized stigma and experiences of enacted stigma are needed.

More research should be carried out to understand the community-level effects of the expansion of ART treatment. It is also needed to determine what activities or conditions need to be in place to enhance the role of increased access to treatment vis-a-vis stigma reduction. The likely rapid expansion of male circumcision programs may also have implications for stigma. Therefore, diagnostic and intervention research is necessary to ensure that men are able to make an informed choice about the procedure without fear of being stigmatized for their circumcision status. Finally, while measures of stigma and discrimination have been validated in specific local contexts, ongoing research is important to assess the validity and reliability of the measures across settings.

In conclusion, HIV-related stigma and discrimination remain key challenges to successful implementation of a host of HIV services and programs. But the Horizons portfolio of projects has moved the field forward to address stigma's root causes and determine effective responses in mitigating its impacts. 


\section{APPENDIX}

\section{Summary of Horizons intervention studies on stigma and discrimination}

\begin{tabular}{|c|c|c|c|c|c|}
\hline Country & $\begin{array}{l}\text { Years of } \\
\text { study }\end{array}$ & Type of intervention & $\begin{array}{c}\text { Target } \\
\text { population }\end{array}$ & Sample size & $\begin{array}{c}\text { Type of study } \\
\text { (sampling technique) }\end{array}$ \\
\hline Brazil & $\begin{array}{l}2002- \\
2005\end{array}$ & $\begin{array}{l}\text { Holistic, non-stigmatizing } \\
\text { health services }\end{array}$ & Male truck drivers & $\begin{array}{l}\text { Baseline: } 1,775 \\
\text { Endline: } 2,415\end{array}$ & $\begin{array}{l}\text { Cross-sectional pre- and post- } \\
\text { intervention evaluation with control } \\
\text { group (systematic sampling) }\end{array}$ \\
\hline India & $\begin{array}{l}2000- \\
2004\end{array}$ & $\begin{array}{l}\text { Staff training, data sharing, } \\
\text { participatory policy } \\
\text { development }\end{array}$ & Hospital workers & $\begin{array}{l}\text { Baseline: } 884 \\
\text { Endline: } 885 \\
\text { (at } 3 \text { hospitals) }\end{array}$ & $\begin{array}{l}\text { Cross-sectional pre- and post- } \\
\text { intervention evaluation (stratified random } \\
\text { sampling) }\end{array}$ \\
\hline Kenya & $\begin{array}{l}2003- \\
2004\end{array}$ & Adherence counseling & People on ART & $\begin{array}{l}\text { Baseline: } 183 \\
\text { Endline: } 181\end{array}$ & $\begin{array}{l}\text { Longitudinal panel study with baseline } \\
\text { and } 12 \text {-month follow up }\end{array}$ \\
\hline Nicaragua & $\begin{array}{l}2002- \\
2005\end{array}$ & $\begin{array}{l}\text { Mass media: communication } \\
\text { for social change }\end{array}$ & $\begin{array}{l}\text { Youth } \\
\text { (ages 13-24 } \\
\text { years) }\end{array}$ & $\begin{array}{l}\text { Participants } \\
\text { completing } \\
\text { surveys at all } 3 \\
\text { intervals: } 3,099\end{array}$ & $\begin{array}{l}\text { Longitudinal panel study with three data } \\
\text { collection intervals, each spaced } 1 \text { year } \\
\text { apart (cluster area random sampling) }\end{array}$ \\
\hline Tanzania & $\begin{array}{l}2001- \\
2006\end{array}$ & $\begin{array}{l}\text { Community awareness \& } \\
\text { mobilization by } \mathrm{NGO}, \\
\text { community leaders }\end{array}$ & $\begin{array}{l}\text { General } \\
\text { population }\end{array}$ & $\begin{array}{l}\text { Baseline: } 978 \\
\text { Endline: } 910\end{array}$ & $\begin{array}{l}\text { Cross-sectional pre- and post- } \\
\text { intervention evaluation (cluster area } \\
\text { random sampling) }\end{array}$ \\
\hline Senegal & $\begin{array}{l}2003- \\
2005\end{array}$ & $\begin{array}{l}\text { Peer education; sensitization } \\
\text { training for STI providers and } \\
\text { media representatives }\end{array}$ & $\begin{array}{l}\text { Men who have } \\
\text { sex with men }\end{array}$ & $\begin{array}{l}\text { Baseline: } 258 \\
\text { Endline: } 290\end{array}$ & $\begin{array}{l}\text { Cross-sectional pre- and post- } \\
\text { intervention evaluation (snowball } \\
\text { sampling) }\end{array}$ \\
\hline Vietnam & $\begin{array}{l}2006- \\
2007\end{array}$ & $\begin{array}{l}\text { Staff training, data sharing, } \\
\text { participatory policy } \\
\text { development, improvements } \\
\text { in structural environment }\end{array}$ & Hospital workers & $\begin{array}{l}\text { Baseline: } 931 \\
\text { Endline: } 889\end{array}$ & $\begin{array}{l}\text { Cross-sectional pre- and post- } \\
\text { intervention evaluation (random, census- } \\
\text { based sampling) }\end{array}$ \\
\hline Zambia & $\begin{array}{l}2001- \\
2002\end{array}$ & $\begin{array}{l}\text { Training of youth members of } \\
\text { "Anti-AIDS Clubs" in care } \\
\text { and support }\end{array}$ & $\begin{array}{l}\text { Youth (13-25) } \\
\text { and people living } \\
\text { with HIV and } \\
\text { their families }\end{array}$ & $\begin{array}{l}\text { Youth: } \\
\text { Baseline: } 796 \\
\text { Endline: } 983\end{array}$ & $\begin{array}{l}\text { Cross-sectional pre- and post } \\
\text { intervention evaluation with comparison } \\
\text { group (random selection of clubs) }\end{array}$ \\
\hline Zambia & $\begin{array}{l}2004- \\
2006\end{array}$ & $\begin{array}{l}\text { Community- and clinic-based } \\
\text { education and mobilization on } \\
\text { HIV, ART, and stigma }\end{array}$ & $\begin{array}{l}\text { General } \\
\text { population; } \\
\text { people on ART }\end{array}$ & $\begin{array}{l}\text { Community } \\
\text { respondents: } \\
\text { Baseline: } 1,203 \\
\text { Endline: } 1,191 \\
\text { People on ART: } \\
\text { Baseline: } 322 \\
\text { Endline: } 501\end{array}$ & $\begin{array}{l}\text { Cross-sectional pre- and post- } \\
\text { intervention evaluation with comparison } \\
\text { group (community respondents: stratified } \\
\text { random sampling; people on ART } \\
\text { recruited sequentially as they came in for } \\
\text { services) }\end{array}$ \\
\hline
\end{tabular}


1. J. Mann, Statement at an informal briefing on AIDS to the 42nd Session of the United Nations General Assembly. New York; 20 October 1987.

2. L. Brown, K. Macintyre, L. Trujillo, "Interventions to reduce HIV/AIDS stigma: what have we learned?" AIDS Education and Prevention 15 (1): 49-69 (2003).

3. R. Parker, P. Aggleton, "HIV and AIDS-related stigma and discrimination: a conceptual framework and implications for action," Social Science and Medicine 57 (1): 13-24 (2003).

4. L. Nyblade, K. MacQuarrie, "Can we measure HIV/AIDS related stigma and discrimination? Current knowledge about quantifying stigma in developing countries (Washington, DC: Policy Project and ICRW, 2006).

5. L. Nyblade et al., "Moving forward: Tackling stigma in a Tanzanian community," Horizons Final Report (Washington, DC: Population Council, 2008).

6. J. Pulerwitz, A. P. Michaelis, "HIV stigma and discrimination," in HIV Testing, Treatment and Prevention: Generic Tools for Operational Research, edited by C. M. Obermeyer (Geneva: World Health Organization, 2009).

7. V. S. Mahendra et al., "Reducing AIDS-related stigma and discrimination in Indian hospitals," Horizons Final Report (New Delhi: Population Council, 2006).

8. V. S. Mahendra et al., "Understanding and measuring AIDS-related stigma in health care settings: A developing country perspective," Journal of Social Aspects of HIVIAIDS Research Alliance 4 (2): 616-25 (2007).

9. K. T. H. Oanh et al., "Improving hospital-based quality of care in Vietnam by reducing HIVrelated stigma and discrimination," Horizons Final Report (Washington, DC: Population Council, 2008).

10. M. Chinaglia et al., "Reaching truckers in Brazil with non-stigmatizing and effective HIV/STI services," Horizons Final Report (Washington, DC: Population Council, 2007).
11. J. Pulerwitz et al., "HIV-related stigma, service utilization, and status disclosure among truck drivers crossing the Southern borders in Brazil," AIDS Care 20 (2): 198-204 (2008).

12. C. I. Niang et al., "'It's raining stones': stigma, violence, and HIV vulnerability among men who have sex with men in Dakar, Senegal," Culture, Health o Sexuality 5 (6): 499-512 (2003).

13. A. Moreau et al., "Implementing STI/HIV prevention and care interventions for men who have sex with men in Senegal," Horizons Research Summary (Washington, DC: Population Council, 2007).

14. I. Solórzano et al., "Catalyzing personal and social change around gender, sexualtiy, and HIV: Impact evaluation of Puntos de Encuentro's communication strategy in Nicaragua," Horizons Final Report (Washington, DC: Population Council, 2008).

15. Horizons Program, "Greater involvement of PLHA in NGO service delivery: Findings from a four-country study," Horizons Research Summary (Washington, DC: Population Council and International HIV/AIDS Alliance, 2002).

16. E. Esu-Williams et al., "We are no longer called club members but caregivers': Involving youth in $\mathrm{HIV}$ and AIDS caregiving in rural Zambia," AIDS Care 18 (8): 888-94 (2006).

17. L. Brown et al., "Psychosocial benefits of a mentoring program for youth-headed households in Rwanda," Horizons Research Summary (Washington, DC: Population Council, 2007).

18. F. Samuels et al., "Engaging communities in supporting HIV prevention and adherence to antiretroviral thereapy in Zambia," Horizons Research Summary (Washington, DC: Population Council, 2008).

19. B. E. Berger, C. E. Ferrans, F. R. Lashley, "Measuring stigma in people with HIV: psychometric assessment of the HIV stigma scale," Research in Nursing and Health 24 (6): 518-29 (2001).

20. S. Kaai et al., "Changes in stigma among a cohort of people on antiretroviral therapy: Findings from Mombasa, Kenya," Horizons Research Summary (Nairobi: Population Council, 2007). 


\section{ACKNOWLEDGMENTS}

The Horizons research studies reviewed in this synthesis paper were conducted in collaboration with the following implementing and research partners, whose cooperation and input were vital: Sharan, Institute of Economic Growth, Tata Institute of Social Sciences, Institute for Social Development Studies, ICRW, Population Council/Brazil, FHI, Puentos de Encuentro, Center for Demographic \& Health Studies UNAN-Leon, Family Health Trust, Mansa Catholic Diocese, Care/ Zambia, World Vision Rwanda, Tulane University School of Public Health, Rwanda School of Public Health, Muhimbili University of the Health Sciences, Kimara Peer Educators and Training Trust, International HIV/AIDS Alliance, Kimirina, CEPAR, INP+, Cheihk Anta Diop University, Senegal National AIDS Control Program, International Centre for Reproductive Health, Institute of Economic and Social Research, Network for Zambian People Living with HIV and AIDS, Traditional Health Practitioners Association of Zambia. The authors would also like to thank Scott Kellerman, Naomi Rutenberg, and LeeAnn Jones of the Population Council; Laura Nyblade and Aparna Jain of ICRW; and Mary Ellsberg of PATH, who provided key support in the writing of this paper. Thanks to Gina Duclayan and Hena Khan for editing and Sherry Hutchinson for layout. 
16 \& Reducing HIV-related Stigma 
Authors: Julie Pulerwitz, Horizons/PATH; Annie Michaelis, Horizons/Population Council; Ellen Weiss, International Center for Research on Women; Lisanne Brown, Horizons/Tulane University; Vaishali Mahendra, Horizons/Population Council
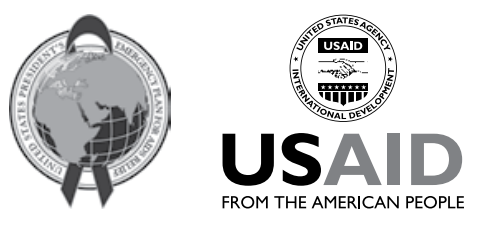

This study and final report were made possible by the President's Emergency Plan for AIDS Relief and the generous support of the American people through the United States Agency for International Development (USAID) under the terms of Cooperative Agreement No. HRN-A-00-97-00012-00. The contents are the responsibility of the Horizons Program and do not necessarily reflect the views of USAID or the United States Government.

Published in April 2010.

1 Population Council The Population Council is an international, non-profit, nongovernmental current and future generations around the world and to help achieve a humane, equitable, and sustainable balance between people and resources. The Council conducts biomedical, social science, and public health research and helps build research capacities in developing countries. Established in 1952, the Council is governed by an international board of trustees. Its New York headquarters supports a global network of regional and country offices.

Copyright (C) 2010. The Population Council Inc.

Suggested citation: Pulerwitz, Julie, Annie Michaelis, Ellen Weiss, Lisanne Brown, and Vaishali Sharma Mahendra. 2010. "Looking back, moving forward: Reducing HIV-related stigma, Horizons studies 2000 to 2007," Horizons Synthesis Background Papers. Washington, DC: Population Council.

This document may be reproduced in whole or in part without permission of the Population Council provided full source citation is given and the reproduction is not for commercial purposes. 


USAID

Population Council

HIV and AIDS Program

4301 Connecticut Ave NW, Suite 280

Washington, DC 20008

Tel: 202-237-9400

Fax: 202-237-8410

pubinfo@popcouncil.org 